\title{
МЕТОДИКА ИЗУЧЕНИЯ СТРАТОТИПОВ В ПРИБАЛТИКЕ
}

Правила описания стратотипов стратиграфических подразделений определены «Стратиграфическим кодексом СССР» (1977). Стратотипы должны быть описаны возможно полнее и точно привязаны к местно. сти, чтобы можно было легко и безошибочно найти их в поле. Полнота и порядок описания стратотипов стратиграфических подразделений разных категорий и рангов, согласно кодексу, должны быть одинаковыми.

Описание стратотипа должно начинаться указанием его местоположения и включать детальную карту или схему (желательно в масштабе 1:10000), показывающую не только расположение обнажения или скважины, но и оптимальные пути подхода. Желательно также приложить аэроснимки и наземные фотографии, чтобы показать географическую протяженность полосы выхода подразделения в типовом районе и положение его границ. В письменной легенде следует указать: название республики, района, сельсовета или поселка, сельскохозяйственного или лесохозяйственного предприятия и его подразделения (отделения колхоза) и точную азимутную и метровую привязку от надежно устанавливаемого элемента рельефа или постройки (от здания, развилки дорог и пр.).

Далее следует привести детальное послойное описание обнажения или группы обнажений, представляющих в совокупности стратотип данного стратиграфического подразделения. Описание нужно снабдить зарисовками стратиграфической колонки и фотографиями, на которых должны быть отображены строение разреза, соотношения, границы и условия залегания всех выделенных в разрезе частей данного подразделения, а также положение и характер его границ с подстилающими и покрывающими стратиграфическими подразделениями. Необходимым условием является четкая маркировка границ стратотипа, которые, по мере возможности, должны быть зафиксированы на фотографиях, зарисовках и обозначены в природе постоянными искусственными отметками настолько детально, чтобы не возникло сомнений в их точном расположении на местности. Для ареальных стратотипов неогенового и четвертичного возраста, а также составных стратотипов любого возраста приводятся дополнительные вырезки из крупномасштабных геологических и геоморфологических карт (а при их отсутствии составляются соответствующие схемы) и профили, показывающие условия залегания и взаимоотношения отдельных частей описываемого стратиграфического подразделения.

Для стратотипов, а также лекто-, нео-, пара- и гипостратотипов, как рекомендуется в «Задачах и правилах изучения и описания стра тотипфв...» (1963), приводят объяснение происхождения названия стратотипического подразделения. Отмечают прежние местные назва- 
ния и ранги подразделения или его значительных частей, если подразделение уже выделялось в том же районе целиком или частично под особыми названиями или индексами.

Колонки и зарисовки обнажений для стратотипов любых категорий и рангов должны отображать особенности строения подразделений, взаимоотношения выделенных элементарных слоев, состав и особенности захоронения фауны и флоры, важнейшие текстурные особенности каждого слоя. Исходя из этого рекомендуется выбирать вертикальный масштаб не мельче $1: 200$, лучше $1: 100$ или $1: 50$. В необходимых случаях делают врезки более крупного масштаба, например, 1:10 или $1: 20$.

Слева от колонки следует приводить название и ранг подразделений или их стратиграфические индексы, номера слоев, ритмов (циклов), виды - индексы зон; справа - масштабную линейку с интервалами глубин, мощности отдельных пачек или слоев; интервалы опробования на все виды анализов, места отбора проб и номера образцов; графически отображают результаты химических, гранулометрических, минералогических и других анализов (рис. 1).

Результаты послойного сбора и изучения палеонтологических остатков, микрофауны, спорово-пыльцевых и других анализов нужно давать либо отдельной колонкой (графой), либо в виде ряда параллельных диаграмм (с указанием интервалов отбора проб и их номеров). Необходимые палеоэкологические зарисовки и диаграммы могут быть в виде врезок или отдельных приложений.

Результаты всех видов опробования следует отображать на диаграммах с учетом строения разреза, изменений литологического состава и структурно-текстурных особенностей слоев (рис. 2), а не механически, соединяя точки опробования. Последнее допустимо лишь внутри литологически однородных слоев и при очень частом (маленьком) интервале опробования (Гричук, Гуртовая, 1981).

Для стратотипов, выделенных по скважинам, рядом с колонкой приводятся диаграммы стандартного электро- и радиоактивного каротажа (Лярская, Савваитова, 1974). В случае несовпадения масштабов параллельно с каротажными диаграммами может быть дана уменьшенная и несколько упрощенная копия литолого-стратиграфической колонки. Однако она должна содержать все необходимые сведения для интерпретации каротажных характеристик, определения границ и строения стратиграфического подразделения. Естественно, что границы подразделения и составляющая его частей, мощности литологических пачек и слоев, показанных на колонке, должны быть предварительно уточнены по каротажу.

Для подразделений, выделенных по обнажениям, в типовом районе выбираются дополнительные разрезы (гипостратотипы) по скважинам с ясно выраженным строением характеризуемого подразделения и возможно более полной каротажной характеристикой.

Послойное описание разреза обычно приводят комплексно, в исторической последовательности, снизу вверх (описание сверху вниз допускается лишь для разрезов буровых скважин). Дают характеристику петрографического состава, структурных и текстурных особенностей пород каждого слоя, состава, сохранности, условий захоронения палеонтологических остатков. Приводят результаты эколого-тафономических, литолого-минералогических исследований, химических анализов; определения абсолютного (физического) возраста отложений радиоуглеродным, калий-аргоновым, урановым и др. методами; палеомагнитные и прочие данные. Перед описанием следует указывать номер слоя, далее в числителе приводить интервал его залегания в метрах, исчисляемый от нижней (или верхней) границы стратотипа, а в знамена- 
теле - мощность. В конце описания каждого слоя должна быть характеристика его верхней границы, для краткости обозначаемая заглавными буквами ВК (верхний контакт).

Послойное описание разреза обычно предваряют краткой характеристикой литологического состава, строения, мощности и возраста подстилающих отложений, списком содержащихся в них палеонтологических остатков, описанием нижней границы выделяемого подразделения. В конце описания стратотипа характеризуют верхнюю границу стратона, после чего приводят краткую характеристику покрывающих подразделений (их возраст, состав, строение, палеонтологическую ха рактеристику, мощность или пределы ее колебаний). Приконтактовые слои подстилающих и покрывающих отложений обязательно указывают на литолого-стратиграфической колонке.

Названия пород приводят с учетом аналитических данных. Для карбонатных пород необходимо учитывать зернистость, содержание карбонатного и другого обломочного материала и органогенного детрита, структурных и текстурных особенностей, указывающих на возможный их генезис и обстановку формирования. Для описания карбонатных пород нижнего палеозоя рекомендуется классификация, разработанная сотрудниками Института геологии АН ЭССР и кафедры геологии Тартуского госуниверситета (Аалоэ, Юргенсон, 1977) либо классификация, предложенная в «Методических рекомендациях по составлению легенд...», (1981), Для описания доломитовых и известняково-доломитовых пород девона рекомендуется морфогенети. ческая классификация В. С. Сорокина (1978).

Названия карбонатно-глинистых пород целесообразно приводить в соответствии с рекомендациями М. С. Швецова (1958). Для их уточнения необходимо выяснить соотношения $\mathrm{CaCO}_{3} / \mathrm{MgCO}_{3}$, содержания песчано-алевритовой и глинистой примеси или хотя бы нерастворимого в 5\%-ном $\mathrm{HCl}$ минерального остатка в породе. Названия терригенных пород следует уточнять по результатам гранулометрического анализа с обязательным выделением границ десятичной классификации и $\varphi$-шкалы Крамбейна, желательно по номенклатуре десятичной классификации. Набор сит точно не регламентируется и зависит от технической возможности исследователя. Описание терригенных пород завершают характеристикой минерального и химического состава вскрытых в данном разрезе образований.

Характеристику минерального состава песчано-алевритового компонента приводят по данным иммерсионного анализа возможно большего количества размерных гранулометрических фракций, предварительно сепарированных в тяжелой жидкости (плотность 2,89 $\mathrm{r} / \mathrm{cm}^{3}$ ) на легкую и тяжелую подфракции. Для сравнения в каждой пробе желательно изучить фракции мелкого ппеска $(0,1-0,25$ мм) и крупного алеврита $(0,05-0,10$ мм), наилучшим образом отвечающие требованиям стратиграфических исследований. Соответствующая рекомендация была сделана уже на первом методическом семинаре литологовминералогов Прибалтики («Ученые записки...», 1965). Отдельно подсчитывают минералы легкой и тяжелой подфракций, в последних отдельно - аллотигенные прозрачные и непрозрачные минералы и аутигенные минералы. Глинистый компонент пород изучают по фракции менее 0,001 или 0,002 мм комплексным методом, в первую очередь рентгеноструктурным, а по возможности, также термическим, химическим и др. Данные гранулометрического и минералогического анали зов целесообразно приводить в сводных колонках (Менс, Пиррус, 1977, рис. 9), а химические анализы основных типов пород - в таблицах.

Для характеристики терригенных пород желательно использовать бороздовое опробование вкрест простирания слоев. Вес проб зависит 
от гранулометрического состава отложений и рекомендуется для песков около $0,2-0,5$ кг, для песчано-гравийных до 3 кг и гравийногалечных - около 10-25 кг. Интервалы отбора проб, т. е. длины борозд, могут варьировать в зависимости от мощности и однородности пачек терригенных пород, но как в кернах, так и в обнажениях не более 2-3 м на каждую пробу. При этом желательно следить не столько за соразмерностью интервалов, сколько за выдержанностью структурно-текстурных особенностей пород.

Разрез стратотипа должен заключать максимальное число коррелятивных признаков, на основании которых выделено и прослеживается данное подразделение (горизонт, свита). К их числу прежде всего относятся макроостатки ископаемых организмов: их следует искать послойно и точно наносить на литолого-стратиграфическую колонку, обозначая номерами, соответствующими номерам в приложенных палеонтологических таблицах. Распространение экологических и систематических групп и видов организмов по разрезу, их количественные соотношения в каждом слое, условия захоронения, экологические характеристики целесообразно отображать графически на самой колонке, рядом с ней (рис. 2) или на отдельных зарисовках (Геккер, 1955, 1957; Лярская, 1981, рис. 6-9, 11-19; Сорокин, 1978, рис. 10, 12 - 15, 22, 26-29, 32, II-VIII; Хинтс, 1979, рис. 4).

Все возрастающую роль при подразделении и корреляции палеозойских отложений играют данные о микрофоссилиях, в особенности о конодонтах, остракодах, а также о граптолоидеях и др. В силу этого фаунистическую характеристику стратотипов необходимо дополнять сведениями о стратиграфическом распространенни различных их групп, об эко- и биозональности. Однако при интерпретации результатов нужно помнить, что на большей части территории Прибалтики палеозой представлен весьма прерывистыми разрезами ритмично (циклически) чередующихся разнофациальных, преимущественно мелководных отложений. В таких условиях, как правило, мы сталкиваемся не с истинными биозонами, а лишь с тейль-зонами, экозонами и разобщенными интервалами обитания групп и видов организмов, более или менее чувствительных к изменениям солености, гидродинамической активности среды, глубины бассейна и других абиотических и биотических факторов.

Следует подчеркнуть также возрастающее значение палеофитологических исследований (особенно палеокарпологического и споровопыльцевого анализа) для корреляции сложно построенных толщ разнофациальных континентальных, лагунных и морских отложений всего фанерозоя (Меннер, 1962; Гричук, Гуртовая, 1981; Кедо, Обуховская, 1981; Величкевич, 1973 и др.). К сожалению, палеофитологическим исследованиям в Прибалтике, особенно при изучении палеозоя, в последние годы уделяется явно недостаточно внимания. Распространившееся мнение, что по спорово-пыльцевым данным (СПД) невозможно выделить и проследить дробные стратипрафические подразделения в разнофациальных толщах (например девона) ввиду выявившейся зависимости СПД от динамики осадконакопления и других палеогеографических условий убедительно опровергаются изучением резекненских, пярнуских и нижненаровских отложений, проведенным Г. И. Кедо, Т. Г. Обуховской (1981), В. Е. Ненастьевой (1981) и другими исследователями.

При микропалеонтологическом опробовании следует иметь в виду, что средний вес проб для извлечения конодонтов сильно варьирует. По данным В. Вийра (1974), для нижне- и среднеордовикских пород он сэставляет, например, несколько сот граммов, а для верхнеордовикских - несколько килограммов. Вес проб для извлечения остракод 


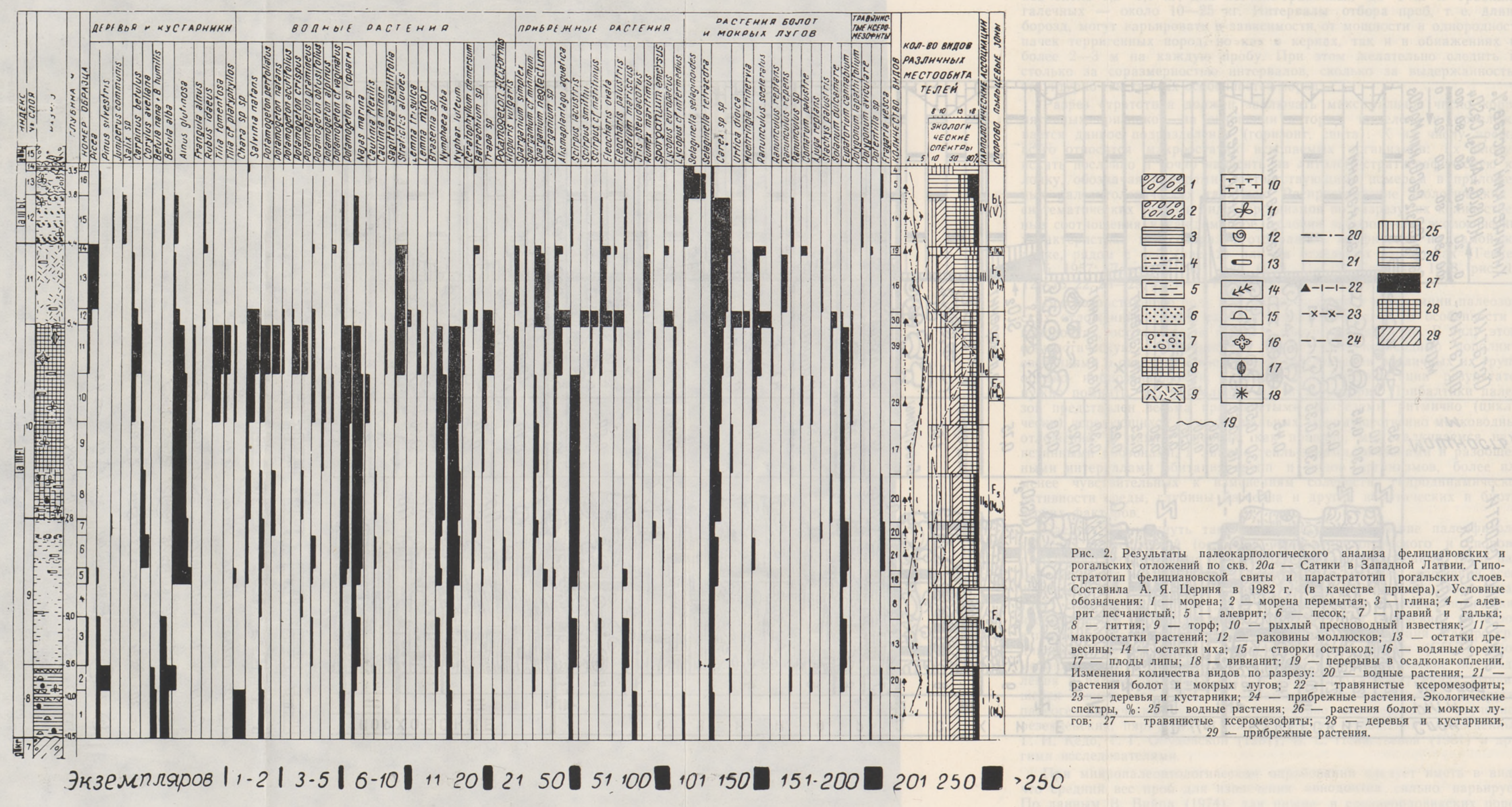


из ордовикских и силурийских пород должен составлять по крайней мере $0,5-1$, для извлечения акритарх из вендских и кембрийских пород около 0,1 , фораминифер из юрских и меловых пород около 0,2 , чешуй рыб из силурийских и девонских пород около 0,4 кг. Ориентировочный вес проб для извлечения хитинозой и микроостатков граптолоидей из нижне- и среднеордовикских пород составляет около 0,1 кг, а из верхнеордовикских - 0,3-0,5 кг. При отборе проб на палинологический анализ из дочетвертичных пород вес проб также варьирует, например от $0,5-1,0$ кг из нижне- и среднедевонских алевролитов до $0,2-0,3$ кг из верхнедевонских голубых глин и мергелей.

На основе упомянутых материалов следует привести краткий анализ стратиграфического и фациально-палеогеографического значения содержащихся в стратотипе комплексов остатков организмов, по возможности, как результат монографического изучения их главнейших групп, а также дать оценку фациальной приуроченности отложений стратотипа. Рекомендуется проанализировать направленность изменения петрографического состава пород, смены фациальных типов отложений и экологических комплексов организмов по разрезу, отметить особенности ритмичного (циклического) строения подразделения.

Стратотипы большинства установленных в Прибалтике горизонтов находятся в пределах распространения мелководных фаций с характерной для них прерывистостью разреза и выпадением отдельных частей подразделений в их типовых районах. Так, кукрузеский горизонт в стратотипическом районе представлен только нижней его частью. Из разреза даугавского горизонта в районе Екабпилса - Риги полностью или почти полностью выпадают ильменские слои. В стратотипе катлешской свиты у Лиелвардского замка в начале огрского времени почти полностью размыта куправская пачка. Отсюда вытекает необходимость выделить гипостратотипы и стратотипы границ ряда горизонтов и свит вне их типовых районов, в пределах палеовпадин, где указанные отложения имеют более полные и непрерывные разрезы, лучше охарактеризованные палеонтологически, либо представленные более глубоководными отложениями. Во многих случаях такие разрезы вскрыты лишь буровыми скважинами в зонах глубокого современного залегания отложений.

В качестве типовых разрезов наиболее пригодны опорные и параметрические скважины, поисковые и структурные также могут служить стратотипами при наличии стандартного каротажа и выноса не менее $60 \%$ керна из интервала стратотипа при проходке по песчаникам и алевролитам и не менее $75-80 \%$ - по карбонатным, сульфатным и глинистым породам. При описании стратотипа по разрезу буровой скважины кроме указанных выше сведений (местоположение, графическое изображение разреза и каротажных кривых, послойное литологическое описание и послойная палеонтологическая характеристика) приводятся сведения о способе бурения, диаметре керна (труб), количестве (в \%) и степени равномерности выноса керна в пределах данного подразделения. С учетом неполноты каменного материала в стратотипе рекомендуется использовать данные о вещественном составе и палеонтологические характеристики парастратотипов, учитывая однако, фациальную изменчивость подразделений.

В конце описания следует указать место хранения образцов (или керна), характеризующих вещественный состав стратотипа и содержащих остатки флоры и фауны; отметить степень их изученности и сохранности. В заключение приводится перечень рекомендаций и мероприятий по дальнейшему изучению и охране стратотипа, с указанием необходимости или желательности выбора нео-, лекто-, гипо- или 
фациостратотипов. Завершать работу должен список литературы по стратотипу.

Описание регионального стратотипа хранится в бюро Прибалтийской PMCK, дубликат его и описания стратотипов местных подразделений - в соответствующих республиканских подкомиссиях. Копии описания стратотипов высылаются в заинтересованные организации с ведома республиканских подкомиссий. Опубликование описаний стратотипов разрешается после их предварительного одобрения республиканской подкомиссией $\mathrm{PMCK}$, на территории которой расположен стратотипический разрез. Установление стратотипов производится согласно Стратиграфическому кодексу СССР.

Изложенные методические рекомендации к изучению стратотипов Прибалтики составлены по заданию Прибалтийской РMCK и в случае необходимости могут быть дополнены и изменены.

\section{ЛИТЕ Р А Т У Р А}

Аалоэ А., Юргенсон Э. Основные типы пород силура Прибалтики. - В кн.: Фации и фауна силура Прибалтики. Таллин, 1977, 14-44.

Величкевич Ф. Ю. Антропогеновые флоры Белоруссии и смежных областей. Минск, 1973.

Вийра B. Конодонты ордовика Прибалтики. Таллин, 1974.

Геккер P. Ф. Наставление для исследований по палеоэкологии. М., 1955.

Геккер Р. Ф. Введение в палеоэкологию. М., 1957.

Гричук В. П., Гуртовая E. E. Межледниковые озерно-болотные отложения у с. Крукеничи. - В кн.: Вопросы палеогеографии плейстоцена ледниковых и перигляциальных областей. М., 1981, 59-91.

Задачи и правила изучения и описания стратотипов и опорных стратиграфических разрезов. М., 1963.

Кедо Г. Н., Обуховская Т. Г. Споры. Средний девон Прибалтики и Северо-Восточной Белоруссии. - В кн.: Девон и карбон Прибалтики. Рига, 1981, 419-436, фототабл. X-XXI.

Лярская Л. А. Панцирные рыбы девона Прибалтики. Рига, 1981.

Лярская Л. А., Савваитова Л. С. Строение и ихтиофауна кетлерской свиты Латвии. - В кн.: Региональная геология Прибалтики. Рига, 1974, 90-106.

Меннер B. В. Биостратиграфические основы сопоставления морских, лагунных и континентальных свит. М., 1962

Менс К. А., Пиррус Э.А. Стратотипические разрезы кембрия Эстонии. Таллин, 1977.

Методические рекомендации по составлению легенд крупномасштабных геологических карт Прибалтикн. Таллин, 1981.

Ненастьева В. Е. Споры. Нижний и средний девон Латвии. - В кн.: Девон и карбон Прнбалтики. Рига, 1981, 410-418.

Сорокин B. C. Этапы развития северо-запада Русской платформы во франском веке. Рига, 1978.

Стратиграфический кодекс СССР. Л., 1977.

Ученые записки Тартуского государственного университета. III. Труды по геологии. Тарту, 1965, вып. 168.

Хинтс Л. Новые данные о распространении брахиопод в йыхвиском горизонте Северной Эстонин. - Изв АН ЭССР. Геол., 1979, 28, 94-99.

Швецов М. С. Петрография осадочных пород. М., 1958.
Ннститут геологии
Академии наук Эстонской ССР
Поступила в редакцию
20/XII 1982

Всесоюзный научно-исследовательский институт морской геологии и геофизики

Литовский научно-исследовательский геологоразведочный институт

Тартуский государственный университет 
A. RAUKAS, V. SOROKIN,

L. PASKEVICIENE, A. ROOMUSOKS

\title{
BALTIMAADE STRATOTUUPIDE UURIMISE METOODIKA
}

Artikkel sisaldab Baltimaade Regionaalse Stratigraafiakomisjoni poolt heakskiidetud regionaalsete ja kohalike stratotüüpide kirjeldamise juhendi ning soovitused proovide vôtmise ja setete või kivimite ainelise koostise määramise kohta, samuti stratotüüpe puudutava materjali säilitamise ja uute stratotüüpide kirjelduste publitseerimise nõuded.

\author{
A. RAUKAS, V. SOROKIN, \\ L. PASKEVICIENE, A. ROOMUSOKS
}

\section{STRATOTYPES STUDY METHODS IN SOVIET BALTIC COUNTRIES}

The paper presents instructions for describing regional and local stratotypes and recommendations for sampling and determination of lithological and mineralogical composition of deposits or rocks, approved by the Baltic Stratigraphic Commission. It also deals with requirements concerning the maintaining of the material on stratotypes and publishing new stratotypes. 